\title{
Practice profiles in breast reduction: A survey among Canadian plastic surgeons
}

\author{
Rebecca A Nelson MD MSc ${ }^{1}$, Shannon M Colohan MD MSc ${ }^{1}$, Leif J Sigurdson MBA MSc MD FRCSC ${ }^{1}$, \\ Don $\mathrm{H}$ Lalonde MSc MD FRCSC ${ }^{2}$
}

RA Nelson, SM Colohan, LJ Sigurdson, DH Lalonde. Practice profiles in breast reduction: A survey among Canadian plastic surgeons. Can J Plast Surg 2008;16(3):157-161.

BACKGROUND: Breast reduction is an increasingly common procedure performed by Canadian plastic surgeons. Recent studies in the United States show that use of the inferior/central pedicle inverted T scar method is predominant. However, it is unknown what the practice preferences are among Canadian plastic surgeons.

OBJECTIVE: The goal of the present study was to assess trends in breast reduction surgery among Canadian surgeons, including patient selection criteria, surgical techniques and outcomes.

METHOD: Surveys were distributed to plastic surgeons at the Canadian Society for Plastic Surgery meetings in 2005 and 2006. Completed surveys were obtained from 140 respondents, and results were analyzed with Excel and SAS software.

RESULTS: There was a $40 \%$ response rate. The majority of surgeons $(66 \%)$ used more than one technique for breast reduction. Most commonly, surgeons use the inverted $\mathrm{T}$ scar technique (66\%) followed by vertical scar techniques $(26 \%)$. The most popular vertical scar techniques included the Hall-Findlay (14\%) and Lejour (13\%) methods. Most surgeons (55\%) reported complication rates of less than $5 \%$ and the most common complication reported was wound dehiscence. There was no difference in overall complication rates between inverted $\mathrm{T}$ scar and vertical scar surgeries. The majority of surgeons (98\%) carried out breast reduction either exclusively as day surgery or in combination with same-day admission. Breast reduction performed as day surgery resulted in cost savings of $\$ 873$ per patient.

CONCLUSIONS: Canadian plastic surgeons are performing more vertical scar breast reductions than American surgeons. However, both groups rely predominantly on inverted $\mathrm{T}$ scar techniques.

Key Words: Breast reduction; Canada; Trend

\section{Bilan des pratiques en matière de réduction mammaire : Sondage mené auprès des chirurgiens plasticiens canadiens}

HISTORIQUE : La réduction mammaire est une intervention de plus en plus pratiquée par les chirurgiens plasticiens canadiens. De récentes études réalisées aux États-Unis montrent que la méthode d'incision en T inversé avec pédicule inférieur/central est privilégiée. Toutefois, on ignore quelles sont les préférences des chirurgiens plasticiens canadiens à cet égard.

OBJECTIF : L'objectif de la présente étude était d'évaluer les tendances en matière de chirurgie pour réduction mammaire chez les chirurgiens plasticiens canadiens, y compris les critères de sélection des patientes, les techniques chirurgicales et les résultats du traitement.

MÉTHODE : Des questionnaires ont été distribués à des chirurgiens plasticiens lors des rencontres de la Société canadienne des chirurgiens plasticiens de 2005 et de 2006. Cent quarante répondants ont soumis leurs questionnaires dûment remplis et les résultats ont été analysés au moyen des logiciels Excel et SAS.

RÉSULTATS : Le taux de réponse a été de $40 \%$. La majorité des chirurgiens $(66 \%)$ utilisaient plus d'une technique pour la réduction mammaire. Le plus souvent, les chirurgiens utilisaient l'incision en T inversé (66\%), suivie de l'incision verticale (26\%). Les techniques d'incision verticale les plus populaires incluaient les méthodes de HallFindlay (14\%) et de Lejour (13\%). Une majorité de chirurgiens (55\%) ont fait état de taux de complications inférieurs à $5 \%$ et la complication la plus courante rapportée était la déhiscence de plaie. On n'a noté aucune différence quant aux taux de complications globaux entre l'incision en T inversé et verticale. La plupart des chirurgiens (98\%) procédaient aux réductions mammaires soit exclusivement sous forme de chirurgie ambulatoire ou en association avec une chirurgie ambulatoire. La réduction mammaire réalisée en chirurgie d'un jour a permis des économies de 873 \$ par patiente.

CONCLUSION : Pour la réduction mammaire, les chirurgiens plasticiens canadiens utilisent l'incision verticale plus que les chirurgiens américains. Toutefois, les deux groupes privilégient les techniques d'incision en T inversé.

survey by Hoffman in 1987 (7) showed that the inframammary scar was the most common reason for litigation against plastic surgeons following breast reduction.

Vertical breast reduction was first described by Dartigues in 1925 (8) and reintroduced by Lassus in 1969 (9), defining a technique that avoided the inframammary fold scar. Lejour modified Lassus' technique $(10,11)$, thereby popularizing the procedure in Europe and South America; however, North American surgeons have been more reluctant to adopt the vertical technique. Explanations include lack of training in vertical techniques, fear of complications, uncertainty regarding perfusion of the superior pedicle, potential for legal action due to substandard results, and apprehension about completing surgery without seeing the final breast shape $(11,12)$. modifications may be associated with problems such as inframammary fold hypertrophic scarring and pseudoptosis (6). A 


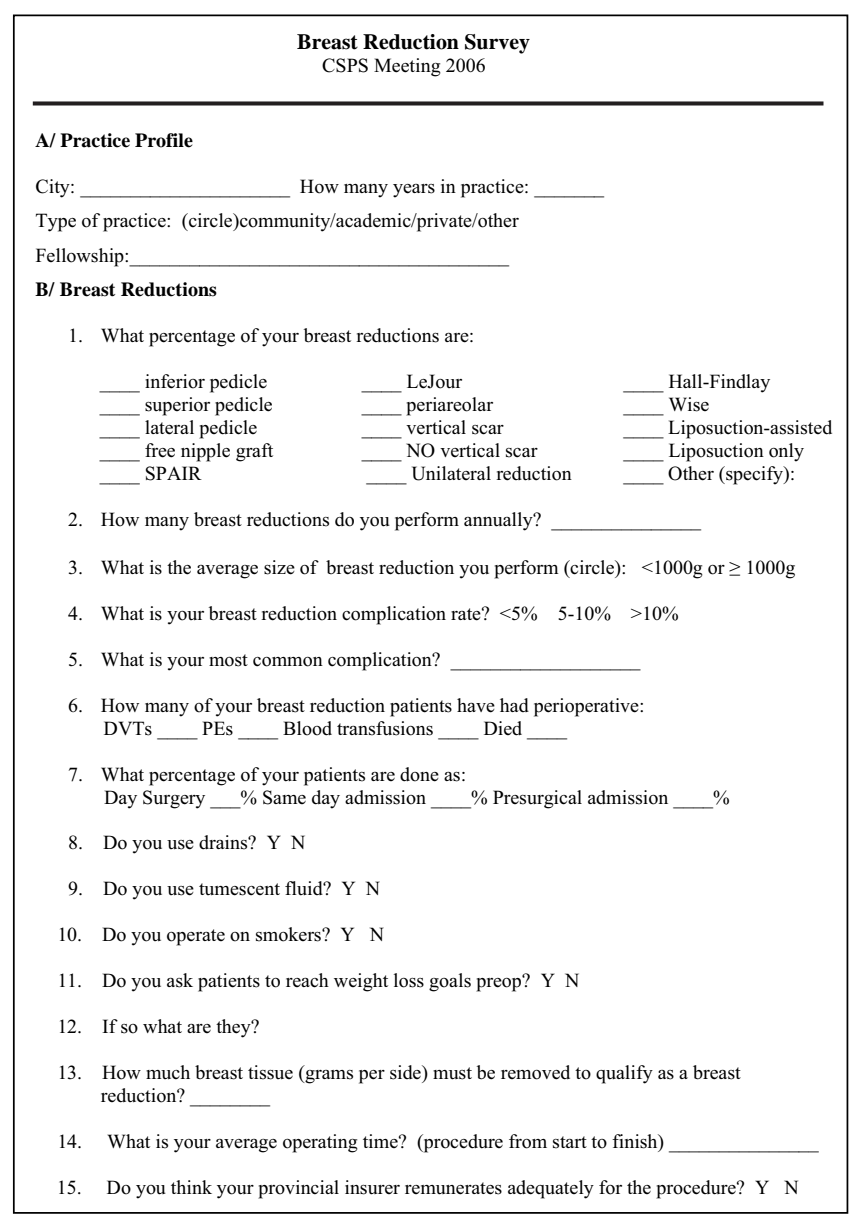

Figure 1) Breast reduction survey from the Canadian Society of Plastic Surgeons (CSPS) meeting in 2006. DVT Deep vein thrombosis; PE Pulmonary embolism; Preop Preoperatively; SPAIR Short scar periareolar inferior pedicle reduction

In a survey of breast reduction techniques among 190 members of the American Society of Plastic and Reconstructive Surgeons, Hidalgo et al (13) found that $74 \%$ of surgeons favored inferior/central pedicle with inverted $\mathrm{T}$ scar techniques. Breast reduction surgery was performed on an inpatient basis $57 \%$ of the time. In a later study, performed in 2002, Rohrich et al (14) surveyed 554 members of the American Society for Aesthetic Plastic Surgery. They found that 75.5\% used primarily inferior pedicle and inverted $\mathrm{T}$ scar techniques, while only $15.5 \%$ of surgeons used limited incision techniques, including short scar and vertical scar methods. Although $89 \%$ of surgeons regarded limited incision techniques and liposuction as new trends that were here to stay, only a fraction of these surgeons were actually using them in practice.

In North America, newer modifications such as the HallFindlay technique, which uses a medial pedicle and vertical scar, have been shown to be safe and efficient (15). Despite these reassurances, comfort with the vertical techniques lag behind Europe.

Menke et al (16) retrospectively reviewed data from 799 breast reduction patients that had been prospectively entered into a database as a form of quality control. They showed that German plastic surgeons performed $99 \%$ of their reductions as inpatient surgery, and that most reductions were less than $1000 \mathrm{~g}$ per side. The majority of reductions $(52 \%)$ were performed using vertical scar techniques, followed by inverted $\mathrm{T}$ scar techniques (45\%). Complication rates were $21.5 \%$, the most common of these being wound dehiscence. There was no difference in complication rates between vertical and inverted $\mathrm{T}$ scar techniques. In the United Kingdom (UK) and Ireland, Iwuagwu et al (17) reported that $67 \%$ of surveyed consultant surgeons use an inferior pedicle technique, mostly on an inpatient basis.

There has been no study to date examining the practice profiles of Canadian plastic surgeons and the types of breast reduction techniques employed. The goal of the present study was to determine which breast reduction techniques Canadian plastic surgeons are using in their practices, and to review complications, outcomes and differential admission costs.

\section{METHODS}

In June 2005, a pilot survey was distributed to 50 Royal College certified plastic surgeons at the Canadian Society of Plastic Surgeons meeting. A second iteration of the survey was then distributed to all Royal College certified senior members of the Canadian Society of Plastic Surgeons in the application package for the 2006 annual meeting $(n=350)$. Nonresponders were not recontacted.

The survey consisted of one page with 15 questions inquiring about practice profile, breast reduction techniques, patient management, complications and provincial remuneration (Figure 1). The majority of questions were categorical, including yes/no and multiple choice answers, and all data were selfreported.

Survey results were tabulated and analyzed. Statistical analysis of results was performed using Excel 2003 (Microsoft, USA) and SAS 9.1 (SAS Institute Inc, USA) software and included Wilcoxon rank sum, $\chi^{2}$ and Student's $t$ tests. Surgical approaches were categorized into pedicle type and scar type. Inverted T scar approaches were placed in the inferior pedicle category and Hall-Findlay reductions were assigned to the medial pedicle category. Other pedicle techniques included central/posterior pedicle, liposuction only and free nipple graft with lower pole amputation. Short scar/vertical scar techniques included all vertical reduction patterns (Lejour, Hall-Findlay), Marchac's vertical scar with short horizontal scar pattern, periareolar scars and L scars (18). Other scar techniques included the liposuction only method. Missing data were placed in an 'unknown' category. For analysis purposes, individuals who performed a scar/pedicle technique more than $50 \%$ of the time were described as performing that technique predominantly.

Cost estimates were provided by the Queen Elizabeth II (Nova Scotia) Hospital Finance Department.

\section{RESULTS}

Of a total of 350 members who were sent surveys, 141 surveys were returned, yielding a response rate of $40.2 \%$. One survey was excluded because the respondent did not perform breast reduction surgery, resulting in 140 eligible surveys.

\section{Practice profile}

The geographical distribution of survey respondents is presented in Figure 2. The majority of surgeons were from British Columbia, Alberta and Ontario. The mean $( \pm S D)$ number of years of practice was $16.2 \pm 9.6$ (range one to 40 years). A large proportion of surgeons practiced in either community (44\%) 


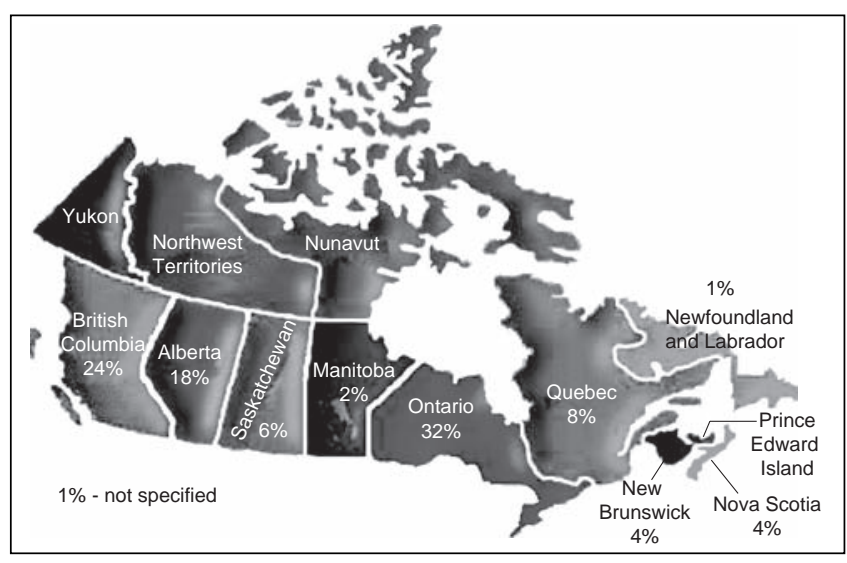

Figure 2) Geographical distribution of breast reduction survey respondents

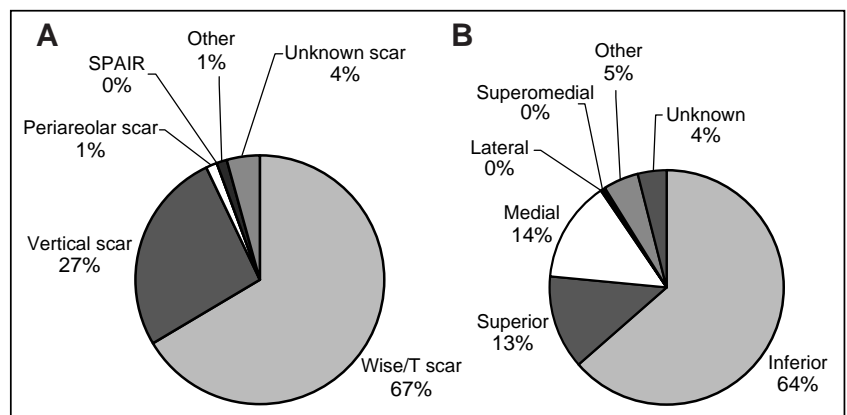

Figure 3) Breast reduction techniques used by Canadian plastic surgeons. A Scar techniques; B Pedicle techniques. SPAIR Short scar periareolar inferior pedicle reduction

or academic settings $(23 \%)$. The remainder of individuals had combined practices $(20 \%)$ or purely private practices $(13 \%)$. Seventy of 140 individuals (50\%) were fellowship trained.

\section{Breast reduction techniques and trends}

The majority of surgeons (66.4\%) used more than one technique for breast reduction. Most reductions were inverted $\mathrm{T}$ scar reductions $(66.2 \%)$. The most commonly used pedicle was the inferior pedicle (63.3\%). Both scar choice and pedicle type can be seen in Figure 3.

Canadian plastic surgeons perform on average $58 \pm 37$ breast reduction cases per year. The vast majority $(87.1 \%)$ involved removal of less than $1000 \mathrm{~g}$ of tissue, and the majority (93.8\%) were bilateral reductions. Individuals who perform predominantly inverted $T$ scar reductions $(n=98)$ were compared with surgeons who use vertical/short scar techniques $(n=42)$ for case loads. There was no significant difference between the average number of annual breast reduction cases performed for inverted $\mathrm{T}$ scar surgeons ( $54.1 \pm 34.5$; range four to 150 cases) versus vertical/short scar surgeons (67.6 \pm 41.9 ; range 13 to 163 cases) $(\mathrm{P}=0.086)$. Similarly, there was no significant difference between size of reduction (less than $1000 \mathrm{~g}$ versus greater than $1000 \mathrm{~g}$ ) when comparing inverted $T$ scar $(n=2$ and $n=42$, respectively) versus limited scar technique surgeons ( $\mathrm{n}=14$ and $\mathrm{n}=98$, respectively) $(\mathrm{P}=0.15)$. On average, surgeons perform $54.8 \% \pm 45.5 \%$ of cases as day surgery, $46.0 \% \pm 46.0 \%$ as same-day admissions and $1.4 \% \pm 10.9 \%$ of cases as preoperative admissions. There were no significant differences between vertical and inverted $\mathrm{T}$ scar surgeons in terms of their admission patterns (all $\mathrm{P}>0.05$ ). Of all surgeons, $42.1 \%$ reported using drains and $32.9 \%$
TABLE 1

Wound complication rates and types

\begin{tabular}{|c|c|c|c|c|}
\hline & \multirow[b]{2}{*}{$\begin{array}{c}\text { Total } \\
(n=140)\end{array}$} & \multicolumn{2}{|c|}{ Breast reduction technique } & \multirow[b]{2}{*}{$\mathbf{P}$} \\
\hline & & $\begin{array}{c}\text { Inverted T } \\
\text { scar }(n=98)\end{array}$ & $\begin{array}{c}\text { Short scar } \\
(n=42)\end{array}$ & \\
\hline Complication rate, n (\%) & & & & 0.363 \\
\hline$<5 \%$ & $77(55.0)$ & $59(60.2)$ & $19(45.2)$ & 0.102 \\
\hline $5 \%-10 \%$ & $41(29.3)$ & $27(27.6)$ & $14(33.3)$ & 0.491 \\
\hline$>10 \%$ & $13(9.3)$ & $7(7.1)$ & $5(11.9)$ & 0.345 \\
\hline Not specified & $6(4.3)$ & $5(5.1)$ & $4(9.5)$ & 0.452 \\
\hline \multicolumn{5}{|l|}{ Complication type, n (\%) } \\
\hline Dehiscence & $59(42.0)$ & $45(46.0)$ & $14(33.3)$ & 0.167 \\
\hline Delayed healing & $38(27.0)$ & $25(26.0)$ & $13(31.0)$ & 0.507 \\
\hline Scar & $8(5.7)$ & $7(7.1)$ & $1(2.4)$ & 0.435 \\
\hline Seroma & $3(2.1)$ & $0(0)$ & $3(7.1)$ & 0.026 \\
\hline Stitch abscess/infection & $9(6.4)$ & $5(5.1)$ & $4(9.5)$ & 0.452 \\
\hline Nipple inversion & $1(0.7)$ & $0(0)$ & $1(2.4)$ & 0.300 \\
\hline Other & $7(5.0)$ & $5(5.1)$ & $2(4.8)$ & 1.000 \\
\hline Ischemic necrosis & $10(7.1)$ & $9(9.2)$ & $4(9.5)$ & 0.066 \\
\hline Not specified & $6(4.3)$ & $2(2.0)$ & $0(0)$ & 0.057 \\
\hline
\end{tabular}

reported using tumescent anesthesia. Surgeons who perform short scar techniques use tumescent anesthesia more often $(54.8 \%$ versus $23.4 \%)$, a difference that was statistically significant $(\mathrm{P}=0.0003)$.

Breast reduction surgery was performed with liposuction by 32 of $140(22.9 \%)$ surgeons, who used it on average $29.5 \%$ of the time. Surgeons using short scar techniques reported more frequent use of liposuction with breast reduction surgery than surgeons performing inverted $\mathrm{T}$ scar techniques $(\mathrm{P}=0.018$ by $\chi^{2}$ ). As a sole technique for breast reduction, liposuction was used by only $6.4 \%$ of surgeons. More than one-half of surgeons (63.6\%) operated on smokers and asked patients to meet preoperative weight goals (54.3\%). Surgeons believe that an average of $287.5 \pm 83.4 \mathrm{~g}$ (range $200 \mathrm{~g}$ to $500 \mathrm{~g}$ ) of breast tissue needs to be removed for surgery to qualify as a breast reduction.

Operative times averaged $119.7 \pm 35.5 \mathrm{~min}$ per surgeon per case, or approximately $2 \mathrm{~h}$. Surgeons using short scar techniques reported shorter average operative time per case than inverted $\mathrm{T}$ scar surgeons $(105.8 \pm 35.2 \mathrm{~min}$ versus $125.9 \pm 33.8$ $\min , \mathrm{P}=0.002$ ).

Only $37.9 \%$ of surgeons believed that remuneration was adequate for breast reduction surgery, while the majority $(60.7 \%)$ believed it was inadequate.

Self-reported complication rates and types can be seen in Table 1 . The majority of surgeons (77 of 140) estimated their complication rates to be less than $5 \%$. The remainder of surgeons (41 of 140; 29.3\%) reported complication rates between $5 \%$ and $10 \%$ and greater than $10 \%$ (13 of 140; 9.3\%). In six surveys, the complication rate was not specified. There were no significant differences in complication rates overall between surgeons who used predominantly inverted $\mathrm{T}$ scar versus vertical and short scar techniques.

The most common complication reported by surgeons overall was wound dehiscence (Table 1). This was followed by delayed healing and ischemic necrosis of skin flaps. There were no significant differences in complications between inverted $\mathrm{T}$ scar versus vertical scar and short scar surgeons with the exception of seroma, which was more common in the vertical and short scar group ( $0 \%$ versus $7.1 \%, \mathrm{P}=0.026$ ). 
TABLE 2

Total number of reported bleeding complications and deaths in breast reduction patients

\begin{tabular}{lcccc}
\hline & $\begin{array}{c}\text { All techniques } \\
(\mathbf{n = 1 4 0 )}\end{array}$ & $\begin{array}{c}\text { Inverted T } \\
\text { scar (n=98) }\end{array}$ & $\begin{array}{c}\text { Short scar } \\
(\mathbf{n = 4 2})\end{array}$ & $\mathbf{P}$ \\
\hline Complication, $\mathrm{n}(\%)$ & & & & \\
Deep vein thrombosis & $44(20.0)$ & $34(35.0)$ & $10(23.8)$ & 0.204 \\
Pulmonary embolism & $23(13.6)$ & $17(17.0)$ & $6(14.3)$ & 0.654 \\
Blood transfusions & $29(11.4)$ & $24(24.0)$ & $2(4.8)$ & 0.004 \\
Deaths & $3(2.1)$ & $2(2.0)$ & $1(2.4)$ & 1.000 \\
\hline
\end{tabular}

Table 2 indicates the total number of reported bleeding complications and deaths in breast reduction patients. Collectively, 28 (20.0\%) surgeons reported having had patients with deep vein thrombosis (DVT) during their careers, with an average of 1.6 DVTs per surgeon (range zero to seven DVTs). There were a total of 44 DVTs reported: 34 in the inverted $\mathrm{T}$ scar surgeons and 10 in the vertical/short scar surgeons. There was no significant difference between the two scar types. Nineteen surgeons (13.6\%) reported having had a patient experience pulmonary embolism (PE) and 16 surgeons (11.4\%) reported having had to use blood transfusion. A total of $23 \mathrm{PE}$ and 29 blood transfusions were reported. There were significantly more blood transfusions reported by inverted $\mathrm{T}$ scar surgeons than by vertical/short scar surgeons $(24.0 \%$ versus $4.8 \%, \mathrm{P}=0.004)$. Only three surgeons (2.1\%) reported death as a complication of breast reduction surgery, and this was not significantly different between the two groups.

\section{Cost analysis}

Day surgery fees per patient at the Queen Elizabeth II Health Sciences Centre were $\$ 300$ for a Canadian resident and $\$ 900$ for nonresidents. The cost of an admission to the ward for any amount of time up to $24 \mathrm{~h}$ was $\$ 1,173$. This covered administration and staffing costs associated with admission to the ward, facility fees and nursing care. Overall, a cost savings of $\$ 873$ occurred when patients were discharged home following breast reduction surgery without inpatient admission. Costs not included in this estimate were surgical billing fees, and fees associated with assessment and testing in the preoperative clinic.

\section{DISCUSSION}

The goal of the present study was to review the practice profiles of Canadian plastic surgeons performing breast reduction, including trends in techniques, complications and costs. Our data indicate that the majority of Canadian surgeons (66.4\%) use more than one reduction technique, and that the most popular technique remains the inverted $\mathrm{T}$ scar $(66.2 \%)$ with inferior pedicle. The next most frequently used technique is the vertical breast reduction $(26.3 \%)$, the most common of these being the Hall-Findlay modification with medial pedicle (14\%), followed by the superior pedicle $(12.9 \%)$. These results suggest that the majority of Canadian plastic surgeons have adapted their practices to include two or more breast reduction techniques that may enable them to accommodate a wider variety of breast shapes and sizes, along with patient preferences.

In comparison with the previously published American studies $(13,14)$, the majority of both Canadian and American surgeons favour the inverted T scar incision. However, a higher proportion of Canadian surgeons use multiple techniques in their surgical practices, which include the vertical scar method of breast reduction. This may be due to differences in surgical training, individual surgeon preference or differences in patient population. It would be interesting to see whether this difference still exists, because the American surveys predate our study by over five years, and changes in surgical technique may have evolved since then. In Canada, this modest trend toward vertical reduction/short scar techniques is one that follows on the heels of similar movements in Europe. A review of breast reduction practices in Germany (16) demonstrated that the most common techniques include vertical scar reductions (52\%) followed by inverted $\mathrm{T}$ scar reductions (45\%). These numbers suggested an increase in the number of vertical reductions performed by German surgeons, reviewed in a subsequent study by Menke et al (16). In the UK and Ireland, the move toward vertical scar reductions is not yet evident; $67 \%$ report using the inferior pedicle technique, whereas only $10 \%$ use a vertical technique such as the LeJour reduction (17).

With regard to practice profile, Canadian surgeons performed more annual breast reductions on average than American surgeons $(58.1 \pm 37$ versus $42.3 \pm 42$, respectively). This was higher than the annual number of reductions performed in the UK and Ireland, where the majority of surgeons performed less than 20 reductions annually (17). Canadian surgeons using predominantly vertical and short scar techniques performed more reductions on average per year than surgeons using predominantly the inverted $\mathrm{T}$ scar, which is also in contrast to our American colleagues. Most reductions performed were less than $1000 \mathrm{~g}$ per side, similar to trends reported by both American (14) and German (16) plastic surgeons. There was no significant difference in percentage of large reductions (greater than $1000 \mathrm{~g}$ ) between inverted T scar and short/vertical scar technique surgeons in our Canadian study; however, it was noted in both the American and German studies that patients undergoing inverted $\mathrm{T}$ scar reductions had generally larger reductions per side than women undergoing vertical scar reductions. Menke et al (16) state that choice of reduction technique was not highly correlated with the size of reduction planned, and that many facilities included in the study performed predominantly one technique, which may have influenced the study results. Intuitively, the general trend toward performing more vertical scar reductions would be consistent with the finding that there was no significant difference between sizes of reduction, as shown in our Canadian survey.

Surgeon-reported complication rates were similar in both American and Canadian breast reductions, with the majority in both groups reporting rates of less than $5 \%$. In contrast to this are the results from the German study (16), which cited a complication rate of $21.5 \%$. This seemingly large difference in complication rates may reflect the recall bias that is likely to have occurred due to retrospective self-reporting of complication rates. Menke et al (16) reported that there was no correlation between technique type and complication rate, with the exception of seroma, present in $3.1 \%$ of vertical reductions compared with $0.8 \%$ of inverted $\mathrm{T}$ scar reductions. Interestingly, the only seromas reported by Canadian surgeons were among those performing vertical reductions. There were no other significant differences in complication rates between Canadian surgeons performing short/vertical scar versus 
inverted T scar reductions, similar to the data of Menke et al. The American surveys did not comment on seroma rates. The most common complication in the American surveys was suture splitting for all techniques, followed by excess scarring (predominantly in the inframammary fold region) in the inverted $\mathrm{T}$ scar group, and need for surgical revision in the short scar group $(13,14)$. Both Canadian and German plastic surgeons reported wound dehiscence as their most common complication (16).

Rare but serious complications reported by Canadian plastic surgeons included DVT and PE. There was no significant difference between technique type and number of DVT/PE reported. In all, $11.4 \%$ of surgeons reported having to administer blood transfusion at least once following breast reduction, and the rate of transfusion was significantly higher among surgeons performing mainly inverted $\mathrm{T}$ scar reductions compared with short/vertical scar reductions $(\mathrm{P}=0.004)$. Although there are no similar rates to compare with in either American or German studies, Menke et al (16) noted that the incidence of autotransfusion among all technique types was $1.6 \%$ and plasma transfusion was $1.4 \%$. Death was rare following breast reduction and was only seen by three surgeons participating in our survey, with no significant difference between this complication and technique type.

Breast reduction surgery was performed as day surgery $(54.8 \%)$ or same-day admission $(48.0 \%)$ by Canadian surgeons. This is in contrast with our German colleagues who, in 2001 , reported that $99 \%$ of reduction mammaplasties were performed as inpatient surgery (16). It is also in contrast with UK data, which showed that $93 \%$ of surgeons never perform outpatient breast reductions (17). Based on our calculations, a cost savings of $\$ 873$ may be achieved by performing breast reductions on an outpatient basis. In our Canadian public health care system faced with escalating costs, more aging

\section{REFERENCES}

1. Miller BJ, Morris SF, Sigurdson LL, et al. Prospective study of outcomes after reduction mammaplasty. Plast Reconstr Surg 2005;115:1025-31.

2. Schnur PL, Schnur DP, Petty PM, Hanson TJ, Weaver AL. Reduction mammaplasty: An outcome study. Plast Reconstr Surg 1997;100:875-83.

3. Aufricht G. Mammaplasty for pendulous breasts; empiric and geometric planning. Plast Reconstr Surg (1946) 1949;4:13-29.

4. Wise RJ. A preliminary report on a method of planning the mammaplasty. Plast Reconstr Surg (1946) 1956;17:367-75.

5. Ribeiro L, Accorsi A Jr, Buss A, Marcal-Pessoa M. Creation and evolution of 30 years of the inferior pedicle in reduction mammaplasties. Plast Reconstr Surg 2002;110:960-70.

6. Reus WF, Mathes SJ. Preservation of projection after reduction mammaplasty: long-term follow-up of the inferior pedicle technique. Plast Reconstr Surg 1988;82:644-52.

7. Hoffman S. Reduction mammaplasty: A medicolegal hazard? Aesthetic Plast Surg 1987;11:113-6.

8. Dartigues L. Traitement chirurgical du prolapsus mammaire. Arch Franc Belg Chir 1925;28:313.

9. Lassus C. Possibilites et limites de la chirurgie plastique de la silhouette feminine. L'Hopital 1969;801:575.

10. Lejour M, Abboud M, Declety A, Kertesz P. [Reduction of mammaplasty scars: from a short inframammary scar to a vertical scar]. Ann Chir Plast Esthet 1990;35:369-79.

11. Lejour M. Vertical mammaplasty: Early complications after 250 personal consecutive cases. Plast Reconstr Surg 1999;104:764-70.

12. Boehm K, Nahai F. Vertical reduction techniques. In: Mathes SM, ed. Plastic Surgery Vol VI. Philadelphia: Saunders Elsevier, 2006:585-99. patients and fewer beds, a surgeon who performs 50 reduction mammaplasties per year as day surgery may save Canadian taxpayers $\$ 43,650.00$ annually by avoiding inpatient admission. Performing reduction as day surgery becomes easier as we improve methods of administering anesthesia, by both local (tumescent) and regional methods, such as the use of paraspinal block for outpatient breast surgery $(19,20)$. In addition to the cost savings, the safety and effectiveness of outpatient breast reduction surgery has been reported in several studies $(21,22)$.

\section{CONCLUSIONS}

The most common method of breast reduction used by Canadian plastic surgeons remains the inverted $\mathrm{T}$ scar technique. Increasing popularity of the vertical scar method is emerging, similar to international trends. There is no difference in self-reported complication rates between surgeons using either method of breast reduction, and the most common complication reported with either technique is wound dehiscence. Canadian plastic surgeons perform the majority of reduction mammaplasties as day surgery, which avoids the cost of inpatient admission. Overall, we see a new trend emerging in Canadian breast reduction surgery practices that includes vertical scar reductions combined with tumescent anesthesia, shorter operative time and the use of liposuction.

DISCLOSURE: The present study has received no external funding and has no commercial or private sponsors. The authors have no conflicts of interest to disclose.

PRESENTATIONS: Canadian Society of Plastic Surgery Annual Meeting, Banff, Alberta (2007). Atlantic Society for Plastic Surgery Annual Meeting, Moncton, New Brunswick (2006).
13. Hidalgo DA, Elliot LF, Palumbo S, Casas L, Hammond D. Current trends in breast reduction. Plast Reconstr Surg 1999;104:806-15.

14. Rohrich RJ, Gosman, AA, Brown SA, Tonadapu P, Foster B. Current preferences for breast reduction techniques: A survey of board-certified plastic surgeons 2002. Plast Reconstr Surg 2004;114:1724-33.

15. Hall-Findlay E. Vertical breast reduction with a medially based pedicle. Aesthetic Plast Surg 2002;22:185.

16. Menke H, Eisenmann-Klein M, Olbrisch RR, Exner K. Continuous quality management of breast hypertrophy by the German Association of Plastic Surgeons: A preliminary report. Ann Plast Surg 2001;46:594-8.

17. Iwuagwu OC, Platt AJ, Drew PJ. Breast reduction surgery in the UK and Ireland - current trends. Ann R Coll Surg Engl 2006;88:585.

18. Jones G. Breast reduction. In: Mathes SM, ed. Plastic Surgery Vol VI. Philadelphia: Saunders Elsevier, 2006:539-84.

19. Naja MZ, Ziade MF, Lönnqvist PA. Nerve-stimulator guided paravertebral blockade vs. general anaesthesia for breast surgery: A prospective randomized trial. Eur J Anaesthesiol 2003;20:897-903.

20. Vila H Jr, Liu J, Kavasmaneck D. Paravertebral block: New benefits from an old procedure. Curr Opin Anaesthesiol 2007;20:316-8.

21. Davies BW, Lewis RD, Pennington GA. Reduction mammaplasty: A comparison of outpatient and inpatient procedures. Aesthetic Plast Surg 1996;20:77-80.

22. Short KK, Ringler SL, Bengston BP, Hunstad JP, Henry E. Reduction mammaplasty: A safe and effective outpatient procedure. Aesthetic Plast Surg 1996;20:513-8. 